\title{
Género en la educación: un desafío para todos...
}

\author{
M. Ed. Beysi De León Quintana
}

"A lo largo de este siglo y, sobre todo, en las últimas décadas, puede decirse que se han dado pasos considerables en el acceso de la mujer en los diferentes niveles y ámbitos educativos". Ana Ayuste $\mathrm{y}$ otros

En todo el mundo, una buena educación es la clave para la construcción de un futuro mejor, ya que ésta ayuda a los individuos a realizarse plenamente. ¿No es éste, acaso, el fin de la educación? Si tomamos como base esta premisa, este ensayo pretende crear en el(la) lector(a) un momento de reflexión crítica sobre la forma en que se desarrolla la experiencia educativa, desde una perspectiva de género en las aulas, y de cómo esta situación influye, día con día, en toda la sociedad. Asimismo, es ésta una clara invitación a los(as) docentes para que rompan con aquellas dinámicas rígidas presentes en el manejo de las clases, las cuales han permitido el afianzamiento de estereotipos que se contraponen a los avances socioeducativos que el país requiere. 
La construcción de género es parte de la cultura, y ésta trae consigo ciertas características esenciales de destacar: es transmitida, es aprendida y es compartida. Por lo tanto, podemos afirmar, que es por medio de la educación (tanto la formal como la informal), la familia, los medios de comunicación y los diferentes grupos sociales, como interiorizamos rasgos socioculturales que marcarán nuestro comportamiento y establecerán roles de conducta que, con el tiempo serán reproducidos.

Es frecuente escuchar en nuestros días, hablar sobre "género", pero para todos no es claro el significado de este término. Hablar de género es referirse a una construcción social que determina los roles, los derechos y las responsabilidades que deben seguir los hombres y las mujeres; lo cual significa que la construcción de género es un proceso histórico y cultural, que por ende, encierra creencias, rasgos de personalidad, actitudes, valores, conductas y actividades que diferencian a las mujeres y a los hombres, mediante procesos de socialización que toman lugar en diferentes esferas macro y micro, como son el Estado, la familia, la escuela, las iglesias, los medios de comunicación y las relaciones interpersonales entre uno y otro sexo. Por eso, para analizar las costumbres, las creencias, los valores y las capacidades de una sociedad y la forma en que se interrelacionan entre sí hombres y mujeres, debemos incluir el género dentro de los sistemas cultural, social y educativo como un eje necesario.

En el ámbito de la familia tradicional, el género existe como un sistema de relaciones desiguales de poder, en contraposición a la idea de unidad armónica y consensual. Los factores de poder se expresan en las jerarquías de género, en donde el rango de superioridad es lo masculino y el de inferioridad es lo femenino, jerarquías que son creadas, reproducidas y mantenidas cotidianamente por sus miembros, 
producto de la división sexual de los trabajos, regulación de la sexualidad y construcciones sociales que, a su vez, se reflejan en los centros educativos.

La familia está íntimamente relacionada no sólo con los aspectos de filiación y de identidad, sino también con los procesos materiales que tienen lugar dentro de ella (alimentación, abrigo, entre otros); y así con otros procesos como la socialización, el aprendizaje del lenguaje, el soporte afectivo o los procesos de reproducción cotidiana. Así pues, es en la familia donde se articula la pertenencia de sus integrantes a los dos mundos: el privado (interno a la familia) y el público (externo a ella).

Generalmente, en nuestras sociedades patriarcales, la familia está directamente relacionada con el papel que desempeña la mujer dentro de ésta. Los roles culturalmente asignados a la mujer, se acompañan de características particulares como la amabilidad, el carácter de servicio, la sumisión, el esmero y otras conductas que son socialmente esperadas del género femenino, no sólo en la familia, sino en el resto de los grupos de la comunidad; mientras que de los hombres se esperan otras conductas.

En este sentido, analizamos que lo aprehendido dentro de la familia tiene una influencia directa no sólo en lo que aprendemos en los salones de clase, sino en lo que transmitimos en ellos. Es decir, la familia y la escuela se corresponden, porque ambas son instituciones que sirven al sistema ideológico dominante, que en nuestras sociedades es de tipo patriarcal. De allí, la dificultad que encuentran los(as) educadores(as) para diluir esquemas tan rígidos en la cotidianidad de las aulas.

Sin duda alguna, también la escuela influye en los procesos que se dan dentro del hogar, dado el afianzamiento de comportamientos. Entonces, el rol que debe desempeñarse dentro de ésta, siguiendo su papel socializador e, 
incluso, atendiendo, explícitamente, los avances legales del país, debe ser el de extender la acción educativa, propiciando vivencias conjuntas que estimulen la equidad entre hombres y mujeres, así como la igualdad de oportunidades. De igual manera, impulsar actividades en las que no sólo participe el estudiante, sino que se involucre a toda la familia y aprovechar estos espacios para fomentar, en todos los ámbitos, el cambio en los significados de género y formación de patrones equitativos y flexibles, en relación con los recibidos en el hogar.

Asimismo, como parte de la acción educativa hacia la comunidad, la escuela debería apuntar hacia la capacitación de todos los miembros de las familias, mediante la adquisición de compromisos más activos en la construcción de una sociedad más justa y solidaria y la instalación en los resquicios que generan las contradicciones del sistema educativo como proceso social, sobre todo, teniendo presente que las experiencias educativas no son iguales para todos, porque no todas las personas son iguales, $y$, el trato que recibe cada uno(a) dentro de las aulas, tampoco es igual.

$\mathrm{Al}$ respecto, podría decirse que la educación en la familia es la primera instancia de tratamiento desigual entre hombres y mujeres y la escuela reafirma ese trabajo. Habitualmente, a la mujer le son atribuidas la afectividad y la dependencia; al hombre, la independencia, la valentía y la ejecutividad. Estos valores son arraigados socialmente y la escuela tiende a reproducirlos. Es más, prevalecen dinámicas grupales consideradas válidas dentro de los procesos educativos que reafirman las diferencias. En los textos didácticos, por ejemplo, a pesar de que han existido variaciones, es notable apreciar la ausencia de la figura femenina en ciertas actividades científicas, políticas y sociales, en las cuales las mujeres ya han tenido y tienen participación activa. En nuestro país, a lo largo de la historia, han existido 
personas que han contribuido grandemente al desarrollo de la sociedad costarricense. Cada uno de ellos, en sus diferentes áreas de acción (política, ciencia, literatura, educación, entre otros), son un ejemplo para las futuras generaciones, y permiten constatar que cada quien desde su sexo, género, creencias y valores, puede aportar significativamente al desarrollo de un pueblo. De allí la importancia de resaltar dentro de las aulas, la labor que tanto hombres como mujeres han llevado a cabo en beneficio de los diferentes ámbitos que conforman nuestra sociedad, forjando de esta manera en nuestros estudiantes, un amplio sentido de compromiso social y respeto a las diferencias.

Otros ejemplos significativos pueden mencionarse como situaciones que pasan casi desapercibidas en la escuela; o bien, se tratan de manera irrelevante: la educación sexual, el embarazo adolescente, la violencia doméstica, el acoso sexual y otros temas que dejan de manifiesto que en la diaria interacción de las escuela, ésta aporta su peso en la construcción de lo que es, socialmente, considerado de importancia de uno u otro género.

Entonces, como educadores y educadoras no podemos permitirnos ver como normal familias inmersas en círculos de agresión, niños y niñas golpeados y ultrajados por sus padres y madres; y mucho menos, podemos ver normal el silencio ante estas situaciones, para no vernos involucrados en entornos difíciles y problemáticos. Es deber del/a educador/a no sólo denunciar estas situaciones, sino comprometerse con la desestructuración de estas dinámicas dentro de los procesos de enseñanza - aprendizaje.

Enmarcar a los jóvenes de osados por sus travesuras y a las niñas como generalmente, más ordenadas y con mejor rendimiento, son otros ejemplos que ilustran nuestra preocupación. De igual manera, seguimos siendo convocados a "reuniones de padres de familia" y en ellas encontramos, 
a lo sumo, uno o dos padres responsables, ya que ésta es una de las labores, tradicionalmente asignadas a las madres, y en las que aún, no logran verse avances significativos en materia de igualdad de oportunidades.

El trabajo escolar docente está también sexualmente dividido, ya que existe gran cantidad de mujeres ejerciendo la docencia, en contraposición a los varones, que, usualmente, se inclinan por otras profesiones, sobre todo, porque esta labor -en el nivel de primaria- se encuentra enmarcada como una de las más "maternalistas", y muchos hombres, aún en este tiempo, no se permiten esa clase de muestras de "debilidad", lo cual reafirma nuestra preocupación, dado que queda también en este ámbito, demostrado el reforzamiento social que se da a la asignación de roles a hombres y mujeres.

Definitivamente, las relaciones desiguales de poder que se manifiestan en la mayoría de las situaciones cotidianas son reforzadas dentro de las aulas por medio del currículum oculto, es decir, mediante todo aquello que la escuela enseña y que no aparece, explícitamente en los textos. Es labor del/a docente tomar conciencia de lo que está sucediendo y resistirse a continuar siendo parte de ese proceso. En esto, cobra fuerza la responsabilidad del sistema educativo, en general, el cual debe decidir sobre los contenidos socializadores y enfrentar con responsabilidad, mediante la inclusión de cambios no sólo en la educación, sino también en las situaciones político-sociales que nos aquejan, haciendo de esta temática una responsabilidad colectiva, íntimamente relacionada con la sociedad que queremos forjar para el mañana.

En relación con el lenguaje y su contribución a estos procesos, este se ha caracterizado históricamente por ser directivo, unidireccional, discriminatorio, prohibitivo y, muchas veces selectivo. La relación esencial evidente entre 
maestro(a) - alumno(a) se manifiesta por medio de la transmisión de información, el premio, el castigo y la evaluación. El ambiente escolar se ha caracterizado por la disciplina, la severidad y el respeto (o el miedo). La educación es vista como la transmisión de contenidos concretos, como transferencia de información, como un bombardeo de datos de una persona que sabe hacia otras que no saben, gracias a una práctica docente, predominantemente, reguladora del comportamiento de los(as) estudiantes. En estos casos, la relación dialógica se obstaculiza y se pierde la perspectiva constructivista del proceso de aprendizaje.

Desde una apreciación genérica, la comunicación en el aula, debe ir mucho más allá de la simple transmisión de contenidos, dado su papel de construcción socio-cultural, ya que, por medio de ésta, se determinan los roles, las características, las pautas de conducta y las formas de relacionarse de los(as) participantes. De allí, la importancia de que el género, que ha sido considerado un eje transversal de la educación, sea realmente incorporado dentro de los contenidos de la asignatura que mejor se presta: Estudios Sociales o Formación Religiosa, y que se promueva, entre otras cosas, la utilización del lenguaje oral y escrito no sexista, para inculcar valores y evitar, de esta forma, infundir en los estudiantes criterios que vayan en contraposición con la equidad de género, no coincidentes con la realidad y con las necesidades actuales.

Entonces, cambiar la forma de utilizar el lenguaje es parte del proceso, ya que la relación lenguaje-pensamiento-mundo es una relación dialéctica, por lo cual la superación del discurso machista (o autoritario), exige la necesidad de empeñarnos en prácticas democráticas.

Debemos recordar que la escuela prepara a los y las jóvenes para formar parte de un mundo globalizado con exigencias cada vez mayores. Es por esto, que no podemos 
obviar la necesidad y el compromiso de los sistemas educativos de formar estudiantes con conciencia social y mente abierta para asumir todo tipo de responsabilidades, respetando la dignidad de las personas y evitando toda discriminación e intolerancia; por lo que debemos considerar que dentro de las aulas, también el afecto, la aceptación de las diferencias individuales (sociales, económicas, etarias y de género), la atención a las necesidades educativas especiales de los(as) alumnos(as) y el uso adecuado de un lenguaje no sexista (expresando aceptación y respeto, primordialmente por medio del diálogo) tienen una importancia fundamental, si lo que se pretende es una educación con equidad de género e igualdad de oportunidades.

Lo anterior, por cuanto el sistema educativo se ha caracterizado por la incorporación de contenidos, los cuales, en gran medida, están desligados de la realidad social que se vive en las comunidades; situación de la cual, aún muchos docentes, a pesar de formar parte de ella, se han visto imposibilitados de incorporar dentro del proceso educativo e, incluso, dentro de sus vidas.

Es necesario que el(la) educador(a) trascienda su conducta consciente, y adopte un estilo de vida y una forma de ser desde el género, por medio de la concienciación y la capacitación constante. Debe sensibilizarse y crear conciencia de que la comunicación entre profesor(a)-alumno(a), en el nivel de contenido y de relación, se da más allá de lo que se comunica verbalmente, respondiendo a lo que es obligatorio enseñar en la vivencia diaria y en el compartir de experiencias, fomentando procesos de cambio cultural tanto en hombres como en mujeres, como por ejemplo, la paternidad responsable y la repartición, en forma equitativa, de las tareas del hogar. De este modo, el currículum oculto transmitiría pautas de conducta no discriminatorias y se comenzaría a cambiar la imagen que todos(as) tienen de su 
condición de hombre o de mujer, inculcada desde su niñez, logrando la construcción de una sociedad más justa y equitativa.

El(la) educador(a) debe adoptar un papel de facilitador(a) en el aula, permitiendo crear ambientes de complementariedad y de respeto a las diferencias de género. Esto implica que el(la) maestro(a) propicie ambientes de diálogo y de aceptación, de comportamientos adecuados que favorezcan la formación de personalidades con características positivas, que estimule la autodeterminación y la independencia, para que, posteriormente, contribuyan a disminuir los casos de agresión y de violencia social y doméstica.

Sabemos que aspirar a un cambio inmediato desde las bases es un proceso complicado por sí mismo, por el solo hecho de depender de la educación no formal de los(as) estudiantes, así como de aspectos sociales sumamente arraigados, y que implica la desestructuración de roles, no sólo dentro de las aulas, sino, también, en el seno de las familias y de la sociedad completa. Pero, además, es éste un proceso progresivo, el cual me atrevería a catalogar de indispensable, sobre todo, por las características socioculturales del grupo del cual formamos parte.

No puede pretenderse crear un caos social con la introducción, en el ámbito escolar, de textos con altos contenidos de diferenciación entre géneros, que provoquen luchas internas en las familias, pero sí debe considerarse la formación docente en este campo y, además, pensarse en el asunto del género como una cuestión relevante y necesaria, que debe ir de la mano de los contenidos y llegar mucho más allá; se convierte en un asunto de conciencia social, de derechos humanos, el cual debe ser asumido, con vasta responsabilidad, por la escuela.

Actualmente, es común, en las aulas, que se enseñe a los y las estudiantes sobre los derechos de los niños y las 
niñas, pero queda la interrogante de si esta temática se aborda desde su esencia, considerando los derechos humanos como parte de los valores que la familia y las instituciones, las que deben sustentarlos y promoverlos. Esto, dado que se encuentran inmersos en un proceso mediante el cual nacen, gradualmente, a partir de determinadas circunstancias que, en general, están caracterizadas por la lucha y la defensa de nuevos derechos y libertades, con miras a incorporar situaciones o experiencias propias de grupos específicos, cuyas necesidades no se ven reflejadas en la cotidianidad.

Es clara la pertinencia de que en el currículum oficial, se haya planteado la equidad de géneros en términos educativos, pero, a su vez, esto refleja la necesidad de mantenerse en pie de lucha, con el fin de generar cambios a lo largo de los procesos educacionales.

Lo anterior, en primera instancia, debido a que la transmisión marcada de roles tradicionales deja huella y se continúa extendiendo a lo largo de los procesos educativos. En segundo lugar, es necesario introducir, en el currículum escolar y en las relaciones en el aula, un conjunto de saberes que han estado ausentes de ellos, así como una mayor valoración de las actitudes y capacidades devaluadas hasta ahora, que deben ser convertidas en conductas por adoptar, tanto para las niñas como para los niños; y enriquecer, así, sus concepciones, a partir de la diversidad cultural reinante en nuestra sociedad.

Es claro que la educación no puede hacer desaparecer las desigualdades, pero es una pieza esencial para disminuirlas, es decir, la educación no garantiza la pluralidad y la igualdad de los géneros en el ámbito social, pero es una condición indispensable para conseguirla.

En este proceso de transformación social, necesario en nuestros días, cuando los índices de violencia de género son alarmantes, el Estado debe llevar la batuta en la búsqueda de 
cambios que promuevan transformaciones sociales y debe ser un canal de posibilidades, para lo cual la escuela debe convertirse en un medio directo, por su carácter socializador, para lograr cambios en uno de los sistemas más cerrados que existen socialmente, pero al cual la educación formal, por el vínculo estrecho con los niños y las niñas, tiene acceso directo: la familia.

Es evidente la necesidad de establecer canales de monitoreo que permitan la evaluación constante de los programas educativos y que promuevan la sensibilidad de género; esto con el fin de poder diseñar estrategias de mejoramiento, que no sólo procuren el cumplimiento de la educación formal para todos(as) los(as) estudiantes, y no simplemente porque las perspectivas de empleo y los ingresos sean mejores si se ha recibido una educación formal, sino porque, durante este proceso, puede lograrse educar jóvenes con conciencia social, con una visión justa de la realidad y, sobre todo, de las necesidades sociales que nos aquejan. Es decir, el Estado debe poner la ecuación a tono con la realidad. La escuela debe contribuir a concienciar a las familias sobre la necesidad de la redefinición de roles y a realizar una revaloración dentro de los hogares y fuera de ellos.

En la escuela, debe fomentarse la integración de los géneros y no las diferencias y las posiciones de subordinación. Para lograrlo, debe procurarse la creación y la difusión de nuevos materiales escolares, que contemplen los aportes de las mujeres y de los hombres a la vida social y a la cultura; deben revisarse los textos educativos con el fin de modificar los errores causados por la visión androcéntrica. Debe considerase, además, el diseño de programas específicos para facilitar a las mujeres el acceso a las nuevas tecnologías y a las profesiones, tradicionalmente, consideradas como masculinas y, de esta manera, evitar la segregación del mercado laboral según el sexo, disminuyendo, así, otras 
formas de discriminación. Igualmente, debe promoverse la modificación del currículum escolar, para dar lugar a los conocimientos y a las experiencias relativas a la salud, a la sexualidad, a las tareas de la vida cotidiana y a las relaciones afectivas.

En fin, podríamos proponer algunas muchas otras alternativas; sin embargo, la esencia de esta propuesta ha sido enmarcada a lo largo de este documento: es indispensable promover el género en la educación, como una responsabilidad de todos. 